\title{
Building Information Modeling (BIM) and the Construction Management Body of Knowledge
}

\author{
Mehmet Yalcinkaya ${ }^{1}$ and David Arditi $^{2}$ \\ ${ }^{1}$ Doctoral Student, Aalto University, Department of Structural Engineering and Building \\ Technology, Espoo, Finland \\ ${ }^{2}$ Professor, Illinois Institute of Technology, Department of Civil, Architectural and \\ Environmental Engineering, Chicago, IL, USA \\ mehmet.yalcinkaya@aalto.fi, \\ arditi@iit.edu
}

\begin{abstract}
Building Information Modeling (BIM) is a process by which a digital representation of the physical and functional characteristics of a facility are built, analyzed, documented and assessed virtually, then revised iteratively until the optimal model is documented. The virtual BIM model is not only graphical design but also a virtual database which includes the management data. So the construction manager $(\mathrm{CM})$ can use BIM as a real simulation of the actual project. However, there is ambiguity about the compatibility of the traditional $\mathrm{CM}$ duties and responsibilities and BIM.

This study looked into the construction management body of knowledge under twelve main subjects relative to the functions of BIM. It was determined that BIM is effective in the most critical phases of a project's lifecycle. The duties and responsibilities of the CM must be updated to improve CMs' efficiency in BIM-based projects.
\end{abstract}

Keywords: Building information modeling (BIM), construction manager (CM), construction management body of knowledge.

\section{Introduction}

Construction management involves the optimum use of available funds, the control of the scope of the work, effective project scheduling, the avoidance of delays, changes and disputes, enhancing project design and construction quality and optimum flexibility in contracting and procurement [1]. Information is of great value for the construction manager (CM). Traditionally, CMs access the necessary information via periodic meetings, blueprints, reports, and work schedules; they coordinate the construction processes with this information. However, preparing and presenting the information is time consuming and includes human factors. It can be stated that traditional methods fall short in monitoring complex construction projects. On the other hand, developments in IT allow the CM to access more accurate and current as well as visual information, which in turn allows the $\mathrm{CM}$ to monitor construction processes more effectively. Developments in IT have affected the CM's duties and responsibilities and therefore, are expected to change the practice of construction management too. 
IT systems used today in construction encompass all disciplines and are used to describe and document the contributions of each member of a project team [2]. The most current IT product is Building Information Modeling (BIM) which is a process by which a digital representation of the physical and functional characteristics of a facility are built, analyzed, documented, and assessed virtually, then revised iteratively until the optimal model is documented [3]. BIM is not only a 3D virtual representation of building, but also a giant database which includes significant information packages for the basic construction management practices such as estimating, scheduling, change orders, etc. So, the designer can use BIM as a real simulation of the actual project before real construction starts. However, there is ambiguity about the compatibility of the construction management body of knowledge and BIM.

Computerization has improved speed and accuracy in most construction management services. Web-based systems have improved access to information, communication between parties and overall efficiency. The basic practices of construction management involve the use of sophisticated computer tools. Budget, schedule, risks, constructability, etc. are modeled and analyzed before the execution of the actual project and tracked during the construction process on the computer screen. These computer tools allow CMs to perform their duties with great speed and accuracy. Most CMs are familiar with traditional practices that involve basic computer tools, but should they also need to get acquainted with BIM and should they explore ways to integrate BIM applications into their duties? The objective of this study is to investigate whether there is a need for updating the current construction management body of knowledge with respect to the emerging BIM technology, hence updating the CM's duties and responsibilities in response to developments in BIM.

\section{$2 \quad$ Methodology}

This study investigates whether the construction management body of knowledge is up to date relative to developments in BIM. The twelve subjects in the body of knowledge were extracted from the Construction Extension to A Guide to the Project Management Body of Knowledge [22]. A comprehensive literature review was performed to understand how BIM affects the basic functions of construction management.

\section{Construction Management and BIM}

\subsection{Budget Management}

Budget management encompasses all project-related cost aspects of CM practice [4]. The CM has the responsibility to confirm, generate, track, report, and substantiate all budgeted costs from the first estimate to the final accounting. The conceptual budget for the project, prepared by the CM before design begins, becomes the team's lineitem financial guide as the design process moves toward the bidding phase. After bids are received, the amounts of accepted contractor proposals replace estimated line-item amounts and become the construction phase budget. As construction proceeds, 
payments to contractors, contract changes, and budgeted expenses are accounted for in detail. Every aspect of project cost is estimated as early as possible and substantiated as it occurs.

One of the important parts of budget management is cost estimating which includes the development of an estimate of the materials and other resources needed to complete the project activities. BIM models can be used for cost estimating to generate a bill of quantities. It is also possible to establish a direct link between the BIM model and the estimating software. Once a cost estimator establishes this link, changes in the BIM model are automatically propagated through the whole estimating cycle [5]. Since there are links between the BIM model and the cost estimate, the CM can get cost-related or expenditure-related evaluation for any activity. Cost budgeting includes allocating the overall cost estimate to individual work activities and controlling the cost of the changes to the project budget. BIM interconnects structural design, time, and cost effectively [6]. Alternative computer-aided methods have been developed for effective budget management. For example, Zhang et al. [7] developed a building information system that includes among other things a budget information and monitoring dimension. Hardin [8] described the use of BIM for effective budget management. Popov et al. [9] stated that cash flow can be predicted in 5D models, where the $5^{\text {th }}$ dimension represents cost-related data.

\subsection{Contract Management}

According to Haltenhoff [4], contract management encompasses the involvement of the $\mathrm{CM}$ in the operational and administrative provisions of the contracts used in the project. Construction management expertise includes the recommendation of standard contract forms and the performance responsibilities to be included in contracts, but does not extend to the writing of contracts or in any way infringe upon the legal profession. This area is important because the construction management system is a unique contracting system, the success of which depends on a workable alignment of traditional contracting roles and participant responsibilities. It is the CM's responsibility to establish a contracting format for the project and see that each contractor's operational and administrative requirements are included.

AGC is the first organization that marketed contract documentation focusing on the use of BIM in a project in September 2007. The "Building Information Modeling (BIM) Addendum" of Consensus DOCS 300 "Tri-Party Collaborative Agreement" promotes an integrated process and focuses on BIM as a tool that can enable the project team. These contracts aim focus on responsible data sharing through BIM technology. AIA has also released contract language that addresses the use of BIM. AIA documents A295-2008, B195-2008 and A195-2008 require protocols for sharing, owning, and transferring data throughout a project [10]. Since BIM brings a new dimension to project delivery methods, the CM should be familiar with these new types of contract.

\subsection{Decision Management}

Decision management encompasses the development and handling of the interrelationships between the project and the construction team, and the relationship 
between the members of the construction team. It is the CM's responsibility to consistently extract decisions from the team without alienating any team members in the process. Team members must make decisions cooperatively, respecting each other's project function, expertise, and operational capacities. Decisions that become contentious must have a prescribed path for resolution.

Since BIM includes all of the design and management source data of the building, the $\mathrm{CM}$ can support the construction team by using BIM applications in the decision making process. Each phase of a project requires a unique decision-making process. The CM can use BIM to generate drawings, reports, design analysis, cost estimates, schedule simulation, facilities management, and ultimately enabling the building team to make informed decisions.

\subsection{Information Management}

Information management encompasses the collection, documentation, dissemination, safe keeping, and disposal of verbal and graphic project-related information. The team structure and the use of multiple contracts significantly increase the information available to the owner. The volume of information generated for project accountability purposes requires a multilevel, need-to-know reporting structure and an efficient information storage and retrieval system [4]. Information management can be established by setting up a communication platform such as BIM. Since BIM is a database of information, the $\mathrm{CM}$ can reach the digitized documents whenever needed and set up a computer-based communication system. Underwood and Isikdag [11] state that BIM acts like a shared information backbone through the lifecycle of the project. The BIM approach is essentially a conceptual way of managing project information even though the majority of construction business processes are heavily based upon traditional means of communication such as face-to-face meetings and the exchange of paper documents in the form of technical drawings, specifications and site instructions. It should be noted that the historical, industrial and market forces that perpetuate the industry's culture affect negatively the extent of adoption of IT tools like BIM [12]. Nevertheless, BIM can be used to communicate with project team members.

\subsection{Material and Equipment Management}

Material/equipment management encompasses all activities relating to the acquisition of materials and equipment from specification to installation and warranty. Material handling includes procurement, inventory, shop fabrication, and field servicing. The construction management delivery system facilitates direct owner purchase of materials for the project. The planning, specifying, bidding, acquisition, expediting, receiving, handling and storing of direct purchases must accurately reflect the requirements of the project schedule. Proper control and management of materials can increase productivity significantly [13]. On the other hand, the use of modern equipment impacts construction technologies and enhances the competitiveness of construction companies. Materials and equipment constitute a large portion of a project's total cost and must therefore be subject to strict control. Organizations that 
do not recognize the impact of various innovations in materials and equipment get forced out of the mainstream of construction activities [14].

4D and 5D BIM models can be used to analyze the time and cost impacts of the selected materials [9]. Also, Mahalingam et al. [15] state that construction planners can use 4D simulations to select the appropriate construction equipment for the project and to check the safety conditions for the movements of equipment. Currently, 4D BIM models are used to optimize site layouts [16], and improve site logistics and space work execution [17].

\subsection{Project Management}

Project management encompasses all of the operational aspects of project delivery, including determining, formulating, developing, installing, coordinating and administering the necessary elements from the beginning of design to the termination of the warranty period. The CM has the responsibility to coordinate the efforts of the team in achieving a common goal.

There is a growing use of BIM models to minimize the potential for design and construction errors, to identify critical space and time during construction [18], to determine the most suitable construction methods and sequence, and to monitor construction progress [19]. Russell et al. [20] discuss how visual representations and interaction technologies support a range of project management functions and enhance the understanding of project status. Song et al. [21] propose a 3D modelbased project management control system that enables the CM to display a holistic picture of a project by applying the multiple project data sets to the $3 \mathrm{D}$ building model components [20]. Zhang et al. [7] use an integrated building information system and digital images captured on-site to semi-automate the calculation of progress measurements and project status.

\subsection{Quality Management}

Quality management ensures that the project will satisfy the needs for which it was undertaken. It includes all activities that determine the quality policy, objectives and responsibilities and implements them by means such as quality planning, quality assurance, quality control, and quality improvement [22]. Since the fundamental element of BIM is a 3D virtual model, the owner and the design team have a first impression of the overall project from the 3D model.

In the traditional approach, it is difficult to reconcile the different designs such as architectural vs. MEP or structural vs. MEP unless the design team is very experienced. However, BIM models allow the design team and the CM to virtually review the conflicts and resolve them during coordination meetings [23]. Therefore, the quality of the project is substantially enhanced before actual construction begins. During the construction process, quality can be controlled with traditional methods such as benchmarking the process against quality standards, but the construction process can be captured and integrated to the BIM environment too. For example, Brilakis et al. [24] experimented with automated construction site image retrieval technologies; Kim et al. [25] explored how 3D models of existing construction sites can be rapidly generated using data from laser scanners; and Akinci et al. [26] 
investigated how as-built laser scan data can be used for ongoing site inspection. The captured construction processes can be used to ensure that the quality requirements of the contract are satisfied.

\subsection{Resource Management}

Resource management includes the selection, organization, direction and use of all project resources, both human and physical. The construction management delivery system places all consulting, design, management, contracting, and construction services in a team environment coordinated by the CM.

BIM technology is used for visualization purposes by most construction professionals. But this technology has moved far beyond its original visualization stage. Some researchers have investigated the integration of construction resource management to BIM. For example, Babic et al. [27] used BIM to link information from the enterprise resource planning (ERP) information system with the building design data, thus tracking the status of the different components of the project; and Wang et al. [28] developed a BIM-based system that integrates dynamic resource management and the decision support system.

\subsection{Risk Management}

Risk management encompasses the dynamic risks that are directly tied to team decisions and static risks that are simply inherent to construction. Risk management has traditionally been applied in the area of safety, cost, time, and contract management in construction projects. It can also be used in bidding policies, feasibility studies, marketability studies, performance evaluations, and contingency management [29].

The $\mathrm{CM}$ can use BIM to reduce safety risks and as a starting point for safety planning and communication. The utilization of BIM can result in improved occupational safety by connecting safety issues more closely to construction planning, providing more illustrative site layout and safety plans, managing and visualizing upto date plans and site status information, as well as by supporting safety communication in various situations [30].

The CM can use BIM to reduce not only safety risks, but also the risks associated with cost and time management. For example, Zhang et al. [7] developed a building information system to address the impact of project management risks on time and cost during the construction of the superstructure of buildings.

\subsection{Safety Management}

Construction is one of the most hazardous industries in the world due to its unique nature including frequent work team rotations, exposure to weather conditions, and high proportions of unskilled and temporary workers [31]. Safety management includes the processes required to assure that the construction project is executed with appropriate care to prevent accidents that cause personal injury, death, or property damage. Accidents and their consequences are a major concern in the construction 
industry both in terms of human suffering and the direct and indirect costs to the industry.

Many researchers have addressed the lack of integration between construction and safety. Traditionally, safety is achieved through periodic meetings and training. Virtualization of the projects before the actual construction phase allows safety managers and CMs to simulate their safety precautions and identify potential safety problems. For example, Popov et al. [9] used 3D simulation to locate cranes such that their booms do not hit structures; Alshawi et al. [32] gave BIM's visualization technologies a central role in safety training; Vacharapoom and Sdhabbon [33] defined a rule-based hazard identification model using BIM to analyze and anticipate unsafe conditions; Sulavinki et al. [30] proposed BIM models to incorporate safety related activities into construction schedules; and $\mathrm{Hu}$ et al. [34] defined the analytical procedures based on $4 \mathrm{D}$ simulations to reveal potential safety threats.

\subsection{Schedule Management}

Construction planners typically use CPM-based networks and bar charts to describe the proposed schedule of a project. The CPM schedule does not provide any spatial information and any information about the complexities of the project components. Therefore to identify the spatial aspects of a project, planners must look at 2D drawings and conceptually associate the components with the related activities. Because CPM networks are an abstract representation of the project schedule, users need to interpret the activities to comprehend the sequence they convey [35]. The outcome could be arbitrary since different planners could have different perspectives of developing a project schedule. In addition, the current CPM methods do not allow planners to explicitly describe the constraints of a construction project, such as availability of resources, the site conditions, and the availability of capital, which are very important factors for making decisions [36]. Therefore, planners can only determine the impact factors of project scheduling in their mind, which is time consuming and frequently prone to error [37]. Besides, it is very difficult to integrate the time and cost information in the current CPM scheduling framework, one of the reasons being that schedules generated by the CPM method are activity-based, whereas in the construction process, the project is executed according to work items. The work items contain the cost and resource data of the project but are not well connected to the activities of the project schedule.

4D models integrate 3D geometry with time as the fourth dimension. Any building component in a 4D model contains geometric attributes that describe its 3D shape, as well as a time attribute that indicates the start and finish times of the construction of this element. A 4D model of a structure can therefore be used to graphically simulate the sequence of construction operations, thereby providing the operator with a virtual, visual understanding of the construction process [2]. 4D visualizations can be used by a wider variety of project participants at varying levels of skills and experience [15].

Some researchers developed integrated systems to schedule projects with basic BIM applications. For example, Dawood et al. [38] proposed a virtual construction site model to develop a decision support system for construction planning; Chau et al. [46] developed and implemented a 4D site management model for construction 
management; Migilinskas and Ustinovichius [39] proposed a 4D model for project life cycle management.

\subsection{Value Management}

Value management addresses a project's cost versus its value, and has three value components: designability, constructability, and contractibility. Designability relates value to overall project design. BIM models allow designers to design a building with respect to the required specifications. Having an effective knowledge about the material libraries makes the virtual model more acceptable. Constructability relates value to construction materials, details, means, methods, and techniques. BIM models allow the design team and the CM to virtually review the conflicts and resolve them during coordination meetings [23]. Current BIM software applications detect clashes and enhance constructability. Contractibility relates value to contracting options, contractual assignments, and contracting procedures. The CM is expected to extract maximum value for the owner with respect to designability, constructability and contractibility.

\section{Conclusion}

The future of the design and construction industry lies in the use of technology; and $\mathrm{BIM}$ is expected to shape this future effectively. The introduction to BIM into design and construction practice has brought along new duties and responsibilities for the CM. However, the existing CM body of knowledge is based on traditional methods despite the fact that BIM is becoming more popular. BIM is effective in every phase of a project's lifecycle as it covers several CM functions in the most critical phases. Hence, traditional CM duties and responsibilities are inadequate in handling the CMrelated functions of BIM-based projects. The consequences of CMs' lack of familiarity with BIM and BIM-related tools may manifest themselves in different ways. Not taking advantage of the benefits provided by 4D and 5D BIM models reduces management efficiency and is detrimental to the overall performance of the project. Therefore CMs' duties and responsibilities must be updated to take full advantage of BIM models.

To understand what BIM brings to the table, the existing CM body of knowledge was reviewed and assessed vis-a-vis the functions of BIM. It was found that modifications are appropriate in almost all of the twelve areas of the CM body of knowledge discussed in the preceding section. For example, CMs must become familiar with tools that help the CM estimate the cost, set up a work schedule, control the cost, improve safety, and manage resources when the architect/engineer uses BIM to design a project; must adjust the organization and management of the team members to take full advantage of the communication and information exchange opportunities provided by BIM; must keep an open mind for integrated project delivery systems that make extensive use of BIM models; must rethink the necessity of constructability reviews in the face of clash detection provided by BIM; and must recognize the changes in the risk distribution that BIM brings to a regular contract. 
An important outcome of this research is related to the potential of BIM to be used alongside many construction management applications. But the literature review indicates that there are differences between traditional and BIM implementation. Therefore, these findings suggest that the current construction management body of knowledge should be updated to reflect the changes caused by BIM in the current construction management duties and responsibilities.

In anticipation of BIM's takeover of design and construction activities, it would be advantageous for all parties to have a common understanding of updated CM duties and responsibilities over all phases of the construction project. Future CMs must be trained to be effective in a BIM environment. If CM education and training keeps abreast of developments such as BIM, CMs can serve the industry better.

In future research, a curriculum can be developed, refined and improved by getting and analyzing feedback from trainees and employers. Also, the effects of BIM on infrastructure projects can be evaluated in future research. It would be interesting to see whether the duties and responsibilities of CMs in BIM-based infrastructure projects are any different than in building projects.

\section{References}

1. Arditi, A., Ongkasuwan, D.: Duties and responsibilities of construction managers: perception of parties involved in construction. Journal of Construction Engineering and Management 135(12), 1370-1374 (2009)

2. Fisher, M., Kunz J.: The scope and role of information technology in construction (2004), http://cife.stanford.edu/online.publications/TR156.pdf (retrieved August 25, 2010)

3. National Institute of Building and Science (NIBS) National building information modelling standards. Facilities information council national BIM standards, Washington, DC (2007)

4. Haltenhoff, C.E.: The CM contracting system, ch. 9, pp. 128-140. Prentice Hall (1998)

5. Staub-Frenc, S., Fischer, M., Kunz, J., Paulson, B.: A generic feature driven activity-based cost estimation process. Advanced Engineering Informatics 17(1), 243-254 (2003)

6. Gabbar, H.A., Aoyama, A., Naka, Y.: Model-based computer-aided design environment for operational design. Computers and Industrial Engineering 46(3), 413-430 (2004)

7. Zhang, X., Bakis, N., Lukins, T.C., Ibrahim, Y.M., Wu, S., Kagioglu, M., Aouad, G., Kaka, A.P., Trucco, E.: Automating progress measurement of construction projects. Automation in Construction 18(3), 294-301 (2009)

8. Hardin, B.: BIM and construction management. Proven tools, methods, and workflows, pp. 176-177. Wiley Publishing Inc., Indianapolis (2009)

9. Popov, V., Juocevicius, V., Migilinskas, D., Ustinovichius, L., Mikalauskas, S.: The use of a virtual building design and construction model for developing an effective project in $5 \mathrm{D}$ environment. Automation in Construction 19(3), 357-367 (2010)

10. AIA, American Institute of Architects Contract documents, Integrated project delivery (IPD) family (2008), http: / / www . aia.org / contractdocs / AIAS 076706 (retrieved August 23, 2010)

11. Underwood, J., Isikdag, U.: Handbook of Research on Building Information Modeling and Construction Informatics: Concepts and Technologies. IGI Global (2010) 
12. Baldwin, A.N., Thorpe, A., Carter, C.: The use of electronic information exchange on construction alliance projects. Automation in Construction 8, 651-662 (1999)

13. Navon, R., Berkovich, O.: Development and On-Site Evaluation of an Automated Materials Management and Control Model. Journal of Construction Engineering and Management 131(12), 1328-1336 (2005)

14. Hendrickson, C.: Project management for construction, Fundamental concepts for owners, engineers, architects and builders. Prentice Hall Publishing, Pitsburg (2008)

15. Mahalingham, A., Kashyap, R., Mahajan, C.: An evaluation of the applicability of 4D CAD on construction projects. Automation in Construction 19(2), 148-159 (2010)

16. Zhang, J., Anson, M., Wang, Q.: A new 4D management approach to construction planning and site space utilization. In: 8th International Conference on Computing in Civil and Building Engineering, ASCE. Stanford University, California, pp. 14-17 (2000)

17. Akinci, B., Fischer, M., Kunz, J., Levitt, R.: Representing Work Spaces Generically in Construction Method Models. Working Paper \#57. CIFE, Stanford University (2000)

18. Dawood, N., Scott, D., Sriprasert, E., Mallasi, Z.: The virtual construction site (VIRCON) tools: an industrial evaluation. Journal of Information Technology in Construction, 43-54 (2005)

19. Sriprasert, E., Dawood, N.: Genetic algorithms for multi-constraint scheduling: an application for the construction industry. In: Proceedings of CIB w78 Conference 2003, Auckland, New Zealand (2003)

20. Russel, A.D., Chiu, C.Y., Korde, T.: Visual representation of construction management data. Automation in Construction 18(8), 1045-1062 (2009)

21. Song, K., Pollalis, S.N., Pena-Mora, F.: Project dashboard: concurrent visual representation method of project metrics on 3D building models. In: ASCE International Conference on Computing in Civil Engineering, pp. 147-153. American Society of Civil Engineers, Reston (2005)

22. Project Management Institute (PMI) Construction extention to a guide to the project management body of knowledge. Project Management Institute, Newtown Square, Pennsylvania (2000)

23. Hartman, T., Gao, J., Fischer, M.: Areas of application for 3D and 4D models on construction projects. Journal of Construction Engineering and Management 134(10), 776785 (2008)

24. Brilakis, I.K., Soibelman, L., Shinagawa, Y.: Construction site image retrieval based on material cluster recognition. Advanced Engineering Informatics 20(4), 443-452 (2006)

25. Kim, H., Haas, C.T., Rauch, A.F.: 3D image segmentation of aggregates from laser profiling. Computer Aided Civil Infrastructure Engineering 18(4), 254-263 (2003)

26. Akinci, B., Boukamp, F., Gordon, C., Huber, D., Lyons, C., Park, K.: A formalism for utilization of sensor systems and integrated project models for active construction quality control. Automation in Construction 15(2), 124-138 (2006)

27. Babic, N.C., Podbreznik, P., Rebolj, D.: Integrating resource production and construction using BIM. Automation in Construction 19(5), 539-543 (2010)

28. Wang, H.J., Zhang, J.P., Chau, K.W., Anson, M.: 4D dynamic management for construction planning and resource utilization. Automation in Construction 13(5), 575-589 (2004)

29. Han, S.H., Kim, D.Y., Kim, H., Jang, W.S.: A web-based integrated system for international project risk management. Automation in Construction 17(3), 342-356 (2008)

30. Sulavinki, K., Kahkonen, K., Makela T., Kiviniemi, M.: 4D-BIM for construction safety planning (2010), http: / / www . cib2010 org/post/files / papers /1167.pdf (retrieved August 24, 2010) 
31. Jannadi, O.A., Bu-Khamsin, M.S.: Safety factors considered by industrial contractors in Saudi Arabia. Building and Environment 37(5), 539-547 (2002)

32. Alshawi, M., Goulding, J., Nadim, W.: Training and education for open building manufacturing: Closing the skills gap. ManuBuild in collaboration with VTT - Technical Research Centre of Finland, Finland (2007)

33. Vacharapoom, B., Sdhabbon, B.: An integrated safety management with construction management using 4D CAD model. Safety Science 48(3), 395-403 (2009)

34. Hu, Z., Zhang, J., Deng, Z.: Construction process simulation and safety analysis based on building information modeling and 4D technology. Tsingua Science and Technology 13, 266-272 (2008)

35. Koo, B., Fischer, M.: Feasibility study of 4D CAD in commercial construction. Journal of Construction Engineering and Management 126(4), 251-260 (2000)

36. Feng, C.W., Chen, Y.J., Huang, J.H.: Using the MD CAD model to develop the time-cost integrated schedule for construction projects. Automation in Construction 19(3), 347-356 (2010)

37. Koo, B., Fischer, M., Kunz, J.: A formal identidication and re-sequencing process of location-based scheduling and 4D CAD. Automation in Construction 16(2), 189-198 (2007)

38. Dawood, N., Akinsola, A., Hobbs, B.: Development of automated communicated of system for managing site information using internet technology. Automation in Construction 11(5), 557-572 (2002)

39. Chau, K.W., Anson, M., Zhang, J.P.: 4D dynamic construction management and visualization software: 1. Development. Automation in Construction 14(4), 512-514 (2005)

40. Migilinskas, D., Ustinovichius, L.: Computer-aided modeling, evaluation and management of construction projects according to PLM concept. In: Luo, Y. (ed.) CDVE 2006. LNCS, vol. 4101, pp. 242-250. Springer, Heidelberg (2006) 